\title{
The Effect of Sputtering Parameters on the Film Properties of Molybdenum Back Contact for CIGS Solar Cells
}

\author{
Peng-cheng Huang, ${ }^{1}$ Chia-ho Huang, ${ }^{1}$ Mao-yong Lin, ${ }^{2}$ Chia-ying Chou, ${ }^{1}$ \\ Chun-yao Hsu, ${ }^{1}$ and Chin-guo Kuo ${ }^{3}$ \\ ${ }^{1}$ Department of Mechanical Engineering, Lunghwa University of Science and Technology, Taoyuan, Taiwan \\ ${ }^{2}$ Department of Mechanical and Electrical Engineering, Fujian Polytechnic of Information Technology, Fujian, Taiwan \\ ${ }^{3}$ Department of Industrial Education, National Taiwan Normal University, Taipei, Taiwan \\ Correspondence should be addressed to Chin-guo Kuo; chinguo7@yahoo.com.tw
}

Received 6 January 2013; Revised 9 February 2013; Accepted 9 February 2013

Academic Editor: Ho Chang

Copyright (C) 2013 Peng-cheng Huang et al. This is an open access article distributed under the Creative Commons Attribution License, which permits unrestricted use, distribution, and reproduction in any medium, provided the original work is properly cited.

\begin{abstract}
Molybdenum (Mo) thin films are widely used as a back contact for CIGS-based solar cells. This paper determines the optimal settings for the sputtering parameters for an Mo thin film prepared on soda lime glass substrates, using direct current (dc) magnetron sputtering, with a metal Mo target, in an argon gas environment. A Taguchi method with an $\mathrm{L}^{9}$ orthogonal array, the signal-to-noise ratio, and an analysis of variances is used to determine the performance characteristics of the coating operation. The main sputtering parameters, such as working pressure (mTorr), dc power $(\mathrm{W})$, and substrate temperature $\left({ }^{\circ} \mathrm{C}\right)$, are optimized with respect to the structural features, surface morphology, and electrical properties of the Mo films. An adhesive tape test is performed on each film to determine the adhesion strength of the films. The experimental results show that the working pressure has the dominant effect on electrical resistivity and reflectance. The intensity of the main peak (110) for the Mo film increases and the full width at half maximum decreases gradually as the sputtering power is increased. Additionally, the application of an Mo bilayer demonstrates good adherence and low resistivity.
\end{abstract}

\section{Introduction}

Copper indium gallium selenium (CIGS) solar cells are highly efficient, low-cost thin film solar cells, and efficiencies of $20.0 \%$ have been reported, so the commercial production of CIGS films is growing rapidly [1]. The CIGS cell uses a substrate, Mo (back contact), CIGS (absorber layer), CdS (buffer layer), $\mathrm{ZnO}$, and $\mathrm{Al}_{2} \mathrm{O}_{3}$-doped $\mathrm{ZnO}$ (window layer), in which each layer has a different role in the working cell [2]. The back contact layer functions as a barrier that hinders the diffusion of impurities from the substrate into the absorber. Molybdenum (Mo) thin films are widely used as a back contact for CIGS-based solar cells. Substrates of Mocoated soda lime glass can be purchased from commercial sources. An Mo back contact with good adherence and low resistivity is essential, because the properties of the Mo thin films significantly affect the performance of CIGS solar cells [3].
Several materials have been with the subjects of experiment for use as a back contact for CIGS thin film solar cells. In order to ensure good electronic device properties, the formation of an ohmic contact for the majority carriers (holes) and a low recombination rate for the minority carriers (electrons) at the CIGS/back contact interface is essential [4]. Compared with other materials, such as $\mathrm{W}, \mathrm{Ta}, \mathrm{Nb}, \mathrm{Cr}, \mathrm{V}$, or Ti, Mo metal is an ideal back contact material for CIGS solar cells, because of its inertness and high conductivity [5]. The advantages of this refractory metal are its low susceptibility to corrosion in a selenium atmosphere and its ability to allow $\mathrm{Na}$ diffusion from a soda lime glass substrate to a CIGS layer.

Traditional experimental methods are too complicated and difficult. These methods require a large number of experiments, when the number of process parameters increases. The Taguchi method increases experimental efficiency and 


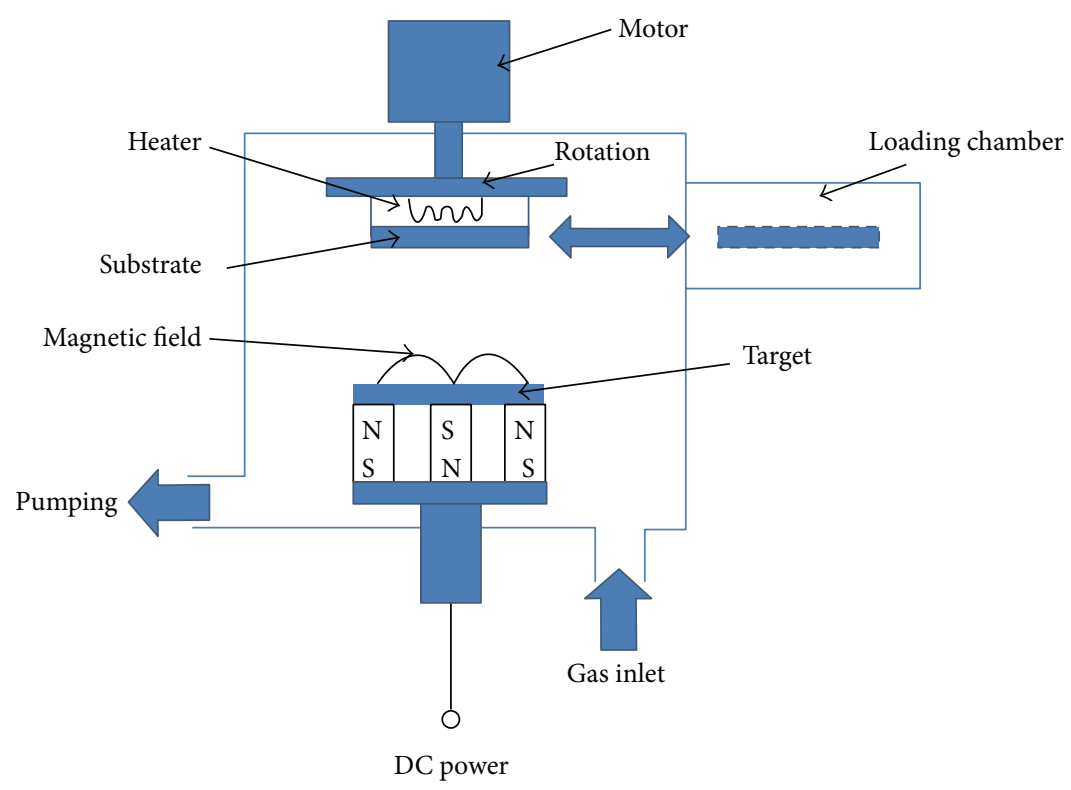

FIGURE 1: Schematic diagram of sputtering system.

allows the design of low-cost products with improved quality [6]. The mixed orthogonal table in the Taguchi quality design derives important coating factors. In order to optimize the process, using the experimental data, a traditional statistical regression requires a large amount of data, leading to difficulty in treating a typical normal distribution of data and a lack of variant factors [7].

This study analyzes the preparation of high quality Mo back contact thin films prepared on soda lime glass substrates, using direct current (dc) magnetron sputtering. Mo films deposited at lower working pressures generally demonstrate poor adherence to the substrate and higher conductivity, but those deposited at higher working pressures tend to demonstrate good adherence and high resistivity [5]. In order to optimize the design of the deposition process for Mo film, this study uses an Mo bilayer to achieve good adherence and low resistivity for Mo films [2].

\section{Experimental Procedure}

Mo thin films were deposited on soda lime glass substrates under various coating conditions, using a $\mathrm{dc}$ magnetron sputtering device, as shown in Figure 1. The diameter of the Mo target (99.95\% purity) was $50.8 \mathrm{~mm}$, and its thickness was $3 \mathrm{~mm}$. The Mo sample was deposited in an argon gas atmosphere, using a base pressure of about $4 \times 10^{-6}$ Torr. The substrate-to-target distance and rotation of the substrate about the vertical axis were maintained at $85 \mathrm{~mm}$ and $10 \mathrm{rpm}$, respectively. Prior to coating, the target was presputtered for $5 \mathrm{~min}$, in order to remove any contamination, and the substrates were ultrasonically cleaned in acetone, rinsed with deionized water, and dried in nitrogen. The magnetron sputtering system was controlled by a microprocessor.
The structure and properties of deposited Mo layers are changed significantly by variations in process parameters, such as working pressure, dc power, and substrate temperature $[8,9]$. Therefore, the optimization process is necessary to improve Mo layers performance. The Taguchi method, which combines experimental design theory and the quality loss function concept, is used for robust design [10]. Three influential sputtering parameters are chosen: working pressure (3, 8, and $13 \mathrm{mTorr})$, dc power $(200,300$, and $400 \mathrm{~W})$, and substrate temperature (room, $100,200^{\circ} \mathrm{C}$ ), each of which is assigned high, medium, and low levels, as shown in Table 1. The Taguchi experimental design uses an $\mathrm{L}_{9}\left(3^{3}\right)$ orthogonal array (Table 2), with three columns and nine rows. Since the $\mathrm{L}_{9}$ orthogonal array has four columns, one column of the array is left empty for the error of experiments: orthogonality is not lost by letting one column of the array remain empty $[11,12]$.

An analysis of variance (ANOVA) was performed, in order to evaluate the coating parameters that were statistically significant. Using the signal-to-noise $(S / N)$ ratio and ANOVA analyses, the optimal combination of the process parameters can be predicted [13]. A confirmation experiment was then conducted to verify the optimal process parameters obtained using these parameters. An ANOVA and an F-test were used to analyze the experimental data as follows:

$$
\begin{gathered}
S_{m}=\frac{\left(\sum \eta_{i}\right)^{2}}{9}, \quad S_{T}=\sum \eta_{i}^{2}-S_{m}, \\
S_{A}=\frac{\left(\sum \eta_{A i}^{2}\right)^{2}}{N}-S_{m}, \quad S_{E}=S_{T}-\sum S_{A}, \\
V_{A}=\frac{S_{A}}{f_{A}}, \quad F_{A o}=\frac{V_{A}}{V_{E}},
\end{gathered}
$$


TABLE 1: Sputtering parameters for Mo thin films, factors, and levels.

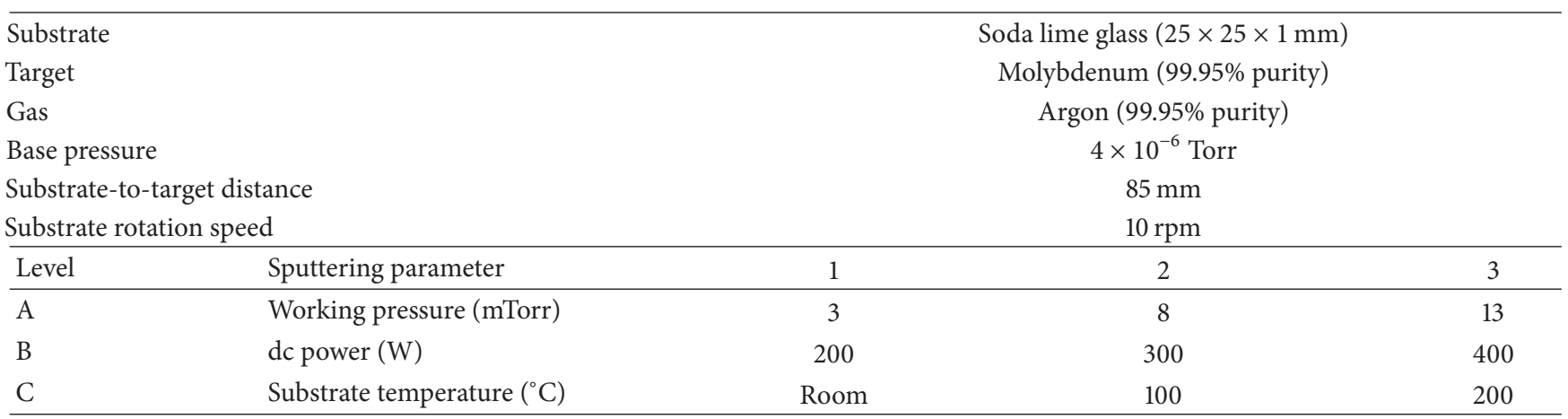

TABLE 2: The $\mathrm{L}_{9}\left(3^{3}\right)$ orthogonal array with three columns and nine rows.

\begin{tabular}{llcc}
\hline No. & \multicolumn{1}{c}{ Control factors } \\
& A & B & C \\
\hline 1 & 1 & 1 & 1 \\
2 & 1 & 2 & 2 \\
3 & 1 & 3 & 3 \\
4 & 2 & 1 & 2 \\
5 & 2 & 2 & 3 \\
6 & 2 & 3 & 1 \\
7 & 3 & 1 & 3 \\
8 & 3 & 2 & 1 \\
9 & 3 & 3 & 2 \\
\hline
\end{tabular}

A: working pressure (mTorr), B: dc power (W), and C: substrate temperature $\left({ }^{\circ} \mathrm{C}\right)$.

where $S_{T}$ is the sum of the squares due to the total variation, $S_{m}$ is the sum of the squares due to the means, $S_{A}$ is the sum of the squares due to parameter $A$ ( $A$ represents working pressure (mTorr), dc power (W), and substrate temperature $\left({ }^{\circ} \mathrm{C}\right)$, resp.), $S_{E}$ is the sum of the squares due to the error, $\eta_{i}$ is the $\eta$ value of each experiment $(i=1, \ldots, 9), \eta_{A i}$ is the sum of the $i$ th level of parameter $A(i=1,2,3), N$ is the repeating number of each level of parameter $A, f_{A}$ is the degree of freedom of parameter $A, V_{A}$ is the variance of parameter $A$, and $F_{A o}$ is the $F$-test value of parameter $A$.

The film thickness was measured using a surface profilometer ( $\alpha$-step, AMBIOS XP-1). The surface morphologies were analyzed using field emission scanning electron microscopy (SEM, JEOL, and JSM-6500F). An atomic force microscope (AFM, PSIA-XE-100) was used to obtain topographic images. The crystalline structural properties were determined by X-ray diffraction (Rigaku-2000 X-ray Generator), using $\mathrm{Cu} \mathrm{K} \alpha$ radiation with an angle incidence of $1^{\circ}$. The electrical resistivity was measured by the four-point probe method (Mitsubishi chemical MCP-T600). The adhesion test was assessed qualitatively, using a Scotch tape adhesion test. The optical reflectance was measured using unpolarized light in the wavelength range of $250 \sim 2000 \mathrm{~nm}$.

\section{Results and Discussion}

In the Taguchi method, the signal-to-noise $(S / N)$ ratio is the most important component of parameter design. The term "signal" represents the desired target for good products, and the term "noise" represents the undesired value. Table 3 shows the ANOVA results for the electrical resistivity of the Mo films; the most important variable affecting the electrical resistivity factor is the working pressure $(P=94.77 \%)$. Figure 2 shows the $S / N$ response graph for the electrical resistivity of the Mo films. It is seen that a lower working pressure and higher dc power result in lower electrical resistivity. In general, at low working pressure, the kinetic energy of the Mo ions is increased, because of decreased particle scattering. As a result, the films become denser structures and are well crystallized, resulting in increased resistivity [14]. However, an increase in dc power causes the Ar ions to bombard the target with higher energy; so greater numbers of Mo particles arrive at the substrate and become deposited layer, which causes the rapid growth of a relatively thick film. An increase in the film thickness results in a decrease in the resistivity of the Mo films [15].

The X-ray diffraction patterns for the Mo films for the $\mathrm{L}_{9}$ orthogonal array from no. 1 to no. 9 are shown in Figure 3(a). The XRD patterns for all of the films show the most intense peak at $2 \theta \sim 40.4^{\circ}$, which is attributed to the Mo cubic structure (JCPDS Card No. 3-065-7442) and a preferred orientation along the (110) direction. All of the Mo films have a sharp (110) peak, which indicates that the Mo films are well crystallized, during the deposition. It is seen that, at lower working pressures (experiments no. 1, no. 2, and no. 3), the diffraction peaks of the Mo films are sharper and more intense, which indicates an improvement in the crystallinity. The reflectivity of the Mo back contact is also a crucial parameter for solar cell efficiency. By maximizing the light reflectance of the back contact, more photons can be absorbed [16]. Figure 3(b) shows that the Mo films deposited at lower working pressures (experiments no. 1, no. 2, and no. 3) demonstrate better reflectivity than those deposited at higher working pressures.

In order to assess the crystalline quality of the Mo films, the full width at half maximum (FWHM) values for the (110) peak and the crystalline dimensions were estimated, 
TABLE 3: ANOVA results for the electrical resistivity of the Mo films.

\begin{tabular}{lcccc}
\hline Factor & Degrees of freedom & Sum of the squares & Variance & Contribution (\%) \\
\hline A & 2 & 1093.37 & 546.684 & 94.77 \\
B & 2 & 28.52 & 14.259 & 2.47 \\
C & 2 & 12.79 & 6.393 & 1.11 \\
Residual error & 2 & 18.94 & 9.470 & 1.65 \\
\hline Total & 8 & 1153.61 & & 100 \\
\hline
\end{tabular}

TABLE 4: Summary of the X-ray diffraction measurements and the results for electrical resistivity, reflection, and adhesion tests.

\begin{tabular}{|c|c|c|c|c|c|c|c|c|}
\hline \multirow{3}{*}{ No. } & \multicolumn{3}{|c|}{ Factors } & \multirow{2}{*}{\multicolumn{2}{|c|}{ XRD }} & \multirow{3}{*}{ Resistivity $(\Omega-\mathrm{cm})$} & \multirow{3}{*}{ Reflection (\%) } & \multirow{3}{*}{ Adhesion (fail/pass) } \\
\hline & & & & & & & & \\
\hline & A & $\mathrm{B}$ & $\mathrm{C}$ & FWHM (110) (deg) & Grain size $(\mathrm{nm})$ & & & \\
\hline 1 & 1 & 1 & 1 & 0.50 & 17.69 & $2.53 \times 10^{-5}$ & 55.40 & Fail \\
\hline 2 & 1 & 2 & 2 & 0.51 & 17.34 & $1.87 \times 10^{-5}$ & 55.22 & Fail \\
\hline 3 & 1 & 3 & 3 & 0.49 & 18.05 & $1.65 \times 10^{-5}$ & 58.87 & Fail \\
\hline 4 & 2 & 1 & 2 & 1.01 & 8.76 & $2.558 \times 10^{-4}$ & 38.63 & Pass \\
\hline 5 & 2 & 2 & 3 & 0.58 & 15.25 & $1.047 \times 10^{-4}$ & 40.11 & Pass \\
\hline 6 & 2 & 3 & 1 & 0.83 & 10.66 & $1.418 \times 10^{-4}$ & 42.90 & Pass \\
\hline 7 & 3 & 1 & 3 & 1.03 & 8.58 & $4.454 \times 10^{-4}$ & 32.47 & Pass \\
\hline 8 & 3 & 2 & 1 & 1.25 & 7.07 & $5.873 \times 10^{-4}$ & 34.55 & Pass \\
\hline 9 & 3 & 3 & 2 & 0.96 & 9.21 & $2.769 \times 10^{-4}$ & 42.97 & Pass \\
\hline
\end{tabular}

TABLE 5: Sputtering parameters for the Mo bilayer and the resultant characteristics.

\begin{tabular}{|c|c|c|c|c|c|c|}
\hline \multicolumn{7}{|c|}{$\mathrm{dc}$ power $400 \mathrm{~W}$, soda lime glass substrate temperature $200^{\circ} \mathrm{C}$} \\
\hline Sample & Mo bilayer & Pressure (mTorr) & Thickness (nm) & $\operatorname{Resistivity~}(\Omega-\mathrm{cm})$ & Reflectance (\%) & Adhesion (fail/pass) \\
\hline \multirow{2}{*}{1} & 1st layer & 13 & 100 & \multirow{2}{*}{$1.79 \times 10^{-5}$} & \multirow{2}{*}{58.80} & \multirow{2}{*}{ pass } \\
\hline & 2nd layer & 3 & 900 & & & \\
\hline \multirow{2}{*}{2} & 1st layer & 13 & 200 & \multirow{2}{*}{$1.87 \times 10^{-5}$} & \multirow{2}{*}{57.03} & \multirow{2}{*}{ pass } \\
\hline & 2nd layer & 3 & 800 & & & \\
\hline \multirow{2}{*}{3} & 1st layer & 13 & 300 & \multirow{2}{*}{$1.99 \times 10^{-5}$} & \multirow{2}{*}{56.82} & \multirow{2}{*}{ pass } \\
\hline & 2nd layer & 3 & 700 & & & \\
\hline \multirow{2}{*}{4} & 1st layer & 13 & 400 & \multirow{2}{*}{$2.52 \times 10^{-5}$} & \multirow{2}{*}{55.61} & \multirow{2}{*}{ pass } \\
\hline & 2nd layer & 3 & 600 & & & \\
\hline \multirow[t]{2}{*}{5} & 1st layer & 13 & 500 & \multirow{2}{*}{$3.26 \times 10^{-5}$} & \multirow{2}{*}{55.40} & \multirow{2}{*}{ pass } \\
\hline & 2nd layer & 3 & 500 & & & \\
\hline
\end{tabular}

using Scherrer's formula. Table 4 summarizes the sputtering parameters for the $\mathrm{L}_{9}$ orthogonal array and the experimental results. Table 4 clearly shows that the parameter set, $\mathrm{A}_{1} \mathrm{~B}_{3} \mathrm{C}_{3}$ (working pressure: $3 \mathrm{mTorr}$, dc power: $400 \mathrm{~W}$, and substrate temperature: $200^{\circ} \mathrm{C}$ ), in experiment no. 3 produces the best performance of the nine experiments. Figure 4 shows the $3 \mathrm{D}$ and 2D AFM images of the surface morphologies and the surface roughness $(\mathrm{Ra})$ of the films, deposited using the experimental conditions (a) no. 3, (b) no. 6, and (c) no. 9. This verifies the relationship between grain size and the sputtering parameters and is consistent with the XRD observation that the grain size increases at a lower working pressure and higher dc power. However, the Mo films deposited at lower working pressure ( 3 mTorr) did not pass the adhesion test as shown in Table 4.
The residual stress changes from a compressive stress to a tensile stress, as the working pressure is increased. Films deposited at high powers and low pressures tend to be more conductive, but these films demonstrate poor adhesion between the Mo film and the substrate, because the films are subject to a compressive stress. Films deposited at a higher pressure tend to be subject to a tensile stress and demonstrate higher resistivity and good adhesion to the glass substrate [5]. In order to obtain the optimal Mo film with lower resistivity and good adhesion, an Mo bilayer film is formed, using a sequentially changing working pressure during the sputtering process. Table 5 lists the sputtering parameters and the properties of the Mo bilayer film. The first bottom layer was deposited at a higher working pressure (13 mTorr), in order to provide better adhesion. Subsequently, 


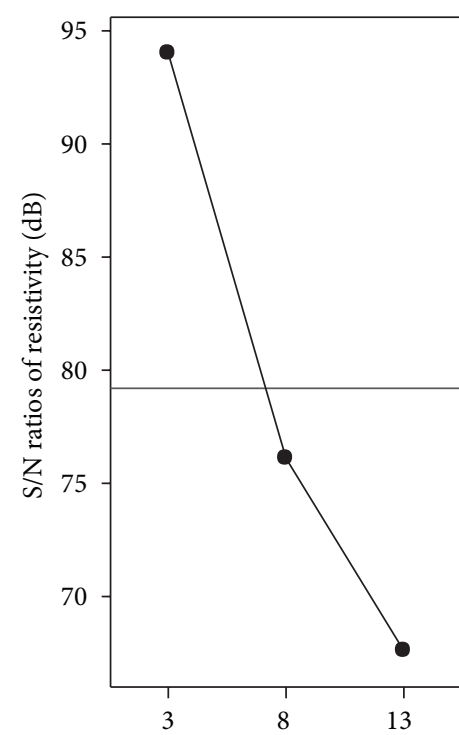

(a)

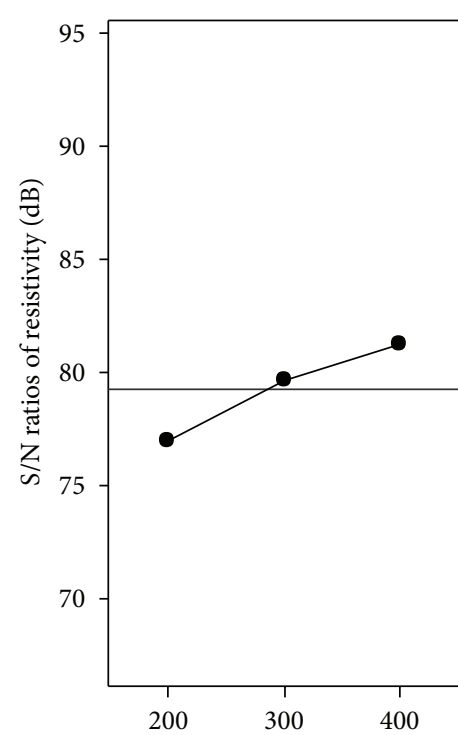

(b)

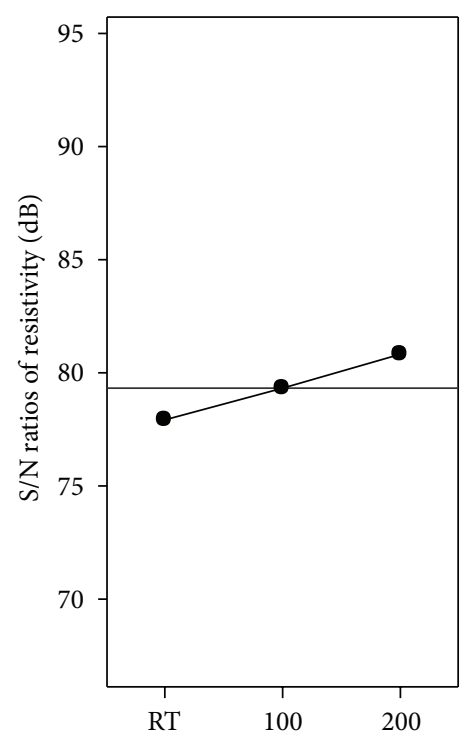

(c)

FiguRE 2: $S / N$ response graph for the electrical resistivity of the Mo films. (a) Working pressure (mTorr), (b) dc power (W), and (c) substrate temperature $\left({ }^{\circ} \mathrm{C}\right)$.

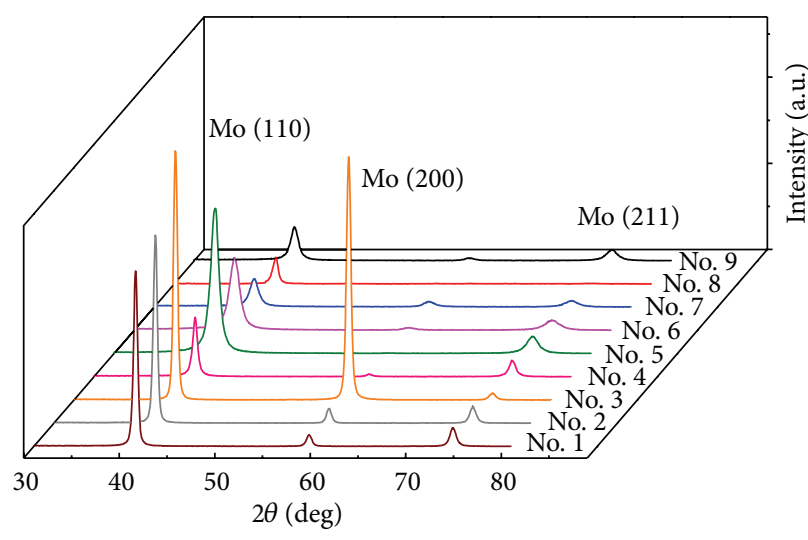

(a)

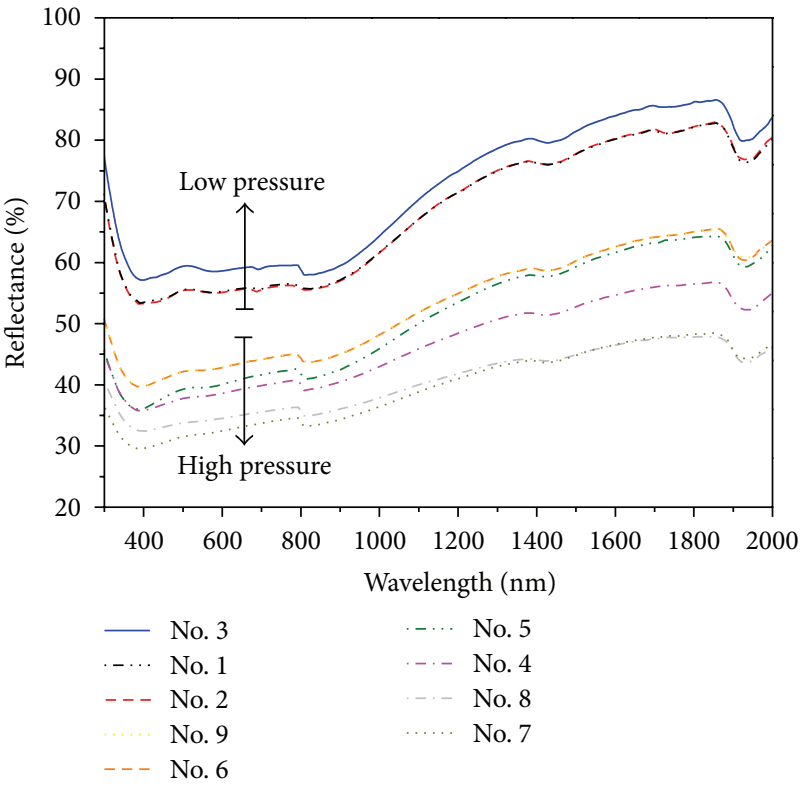

(b)

FIgURe 3: Mo films grown on glass for the $\mathrm{L}_{9}$ orthogonal array from no. 1 to no. 9: (a) XRD patterns and (b) reflectance.

the second top layer was formed at a lower working pressure ( 3 mTorr), in order to produce a lower resistivity. All of the Mo bilayers passed the Scotch tape test. An Mo bilayer with optimal properties was produced (sample 1) with the 1st layer being deposited at 13 mTorr (thickness was $100 \mathrm{~nm}$ ) and the 2 nd layer being deposited at 3 mTorr (thickness was $900 \mathrm{~nm}$ ), which demonstrated good adhesion, low resistivity $\left(1.79 \times 10^{-5} \Omega-\mathrm{cm}\right)$, and high reflectance $(58.80 \%)$. Figure 5 shows the surface (left) and cross-sectional (right) SEM micrographs of the Mo bilayer films detailed in Table 5. The 1st layer was deposited at a high working pressure and the 2 nd layer at a low working pressure. The total layer $(1 \mathrm{st}+2 \mathrm{nd})$ thickness is $1000 \mathrm{~nm}$. All of the films exhibited a columnar structure with faceted and elongated surface features. In Figure 5(a), it is seen that sample 1 has a larger grain size, which results in a reduced resistivity. 

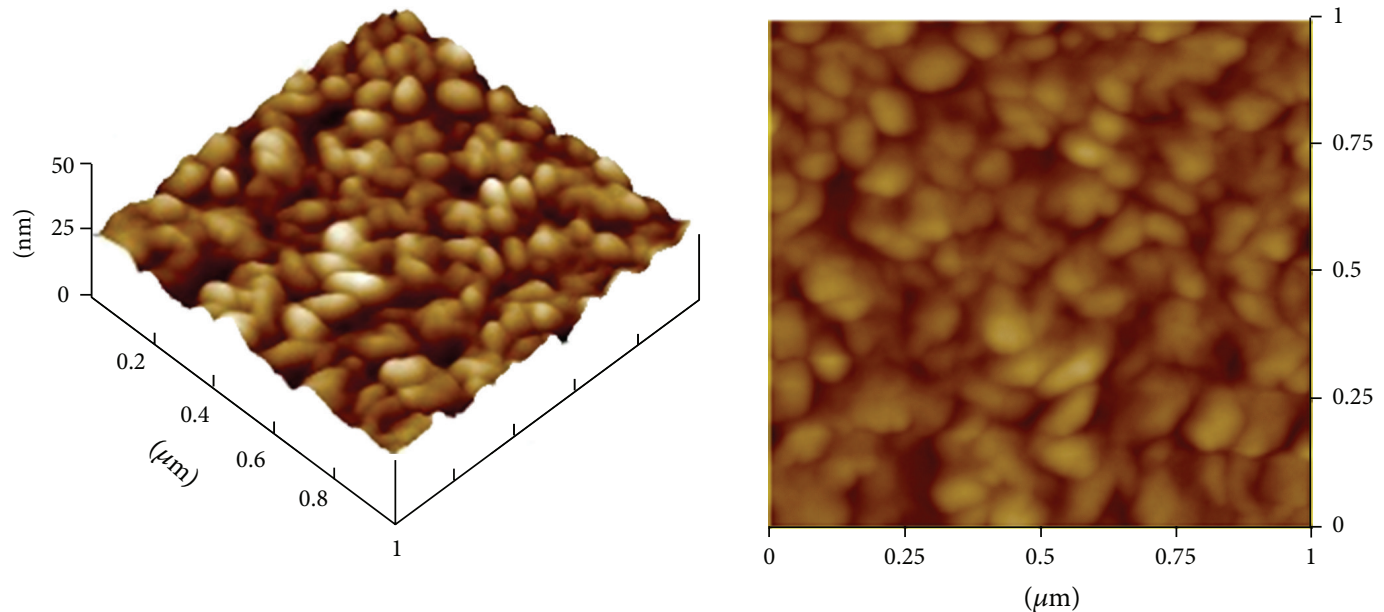

(a)
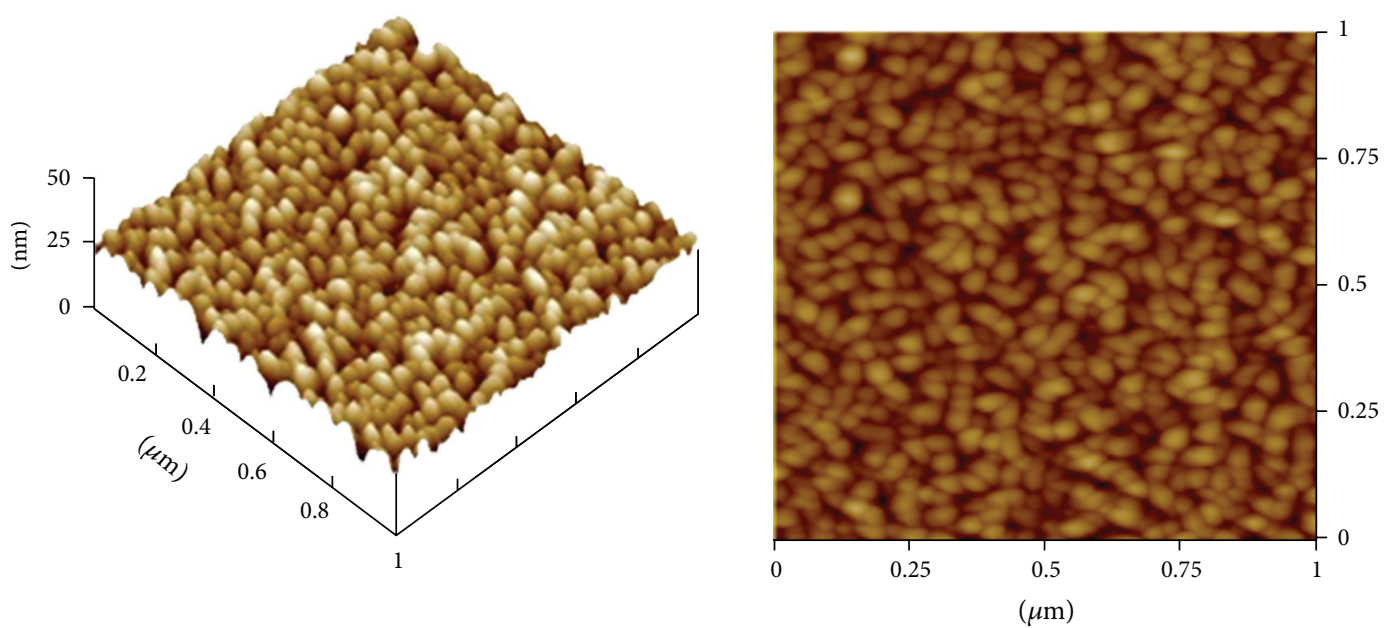

(b)
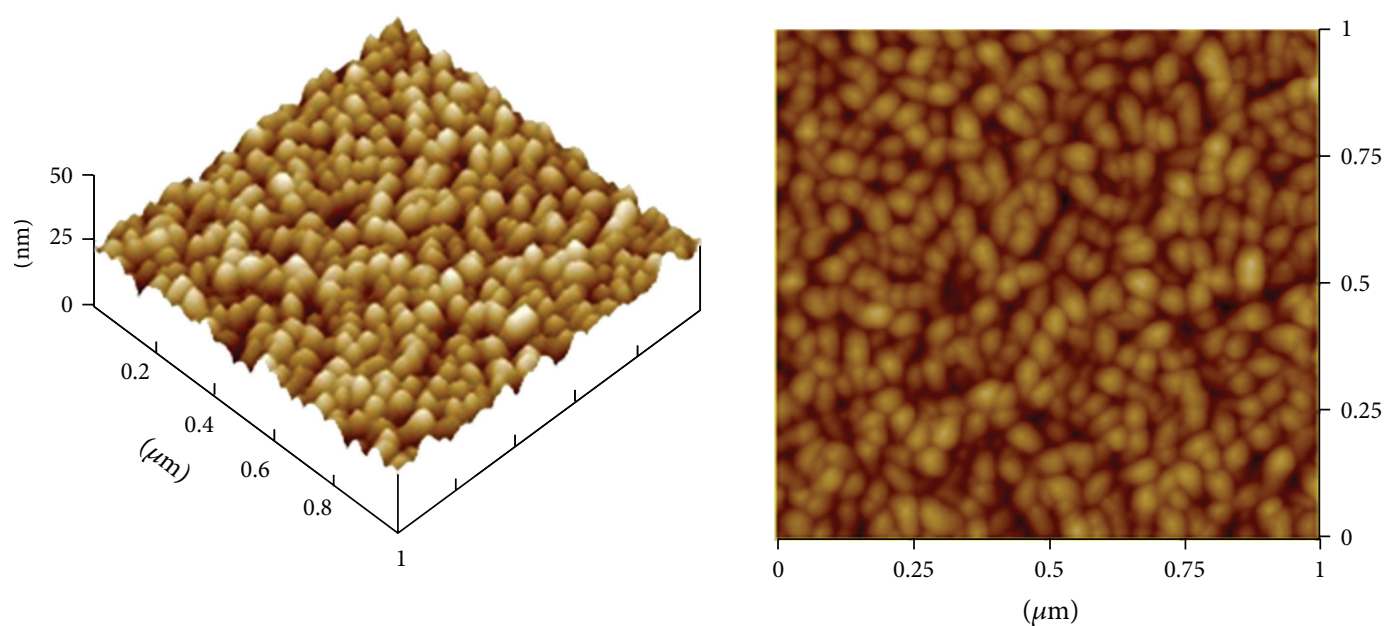

(c)

FIGURE 4: AFM images (left 3D and right 2D) of Mo thin films deposited using various sputtering parameters: (a) experimental conditions no. $3, \mathrm{Ra}=2.703 \mathrm{~nm}$; (b) no. $6, \mathrm{Ra}=3.132 \mathrm{~nm}$; and (c) no. $9, \mathrm{Ra}=3.121 \mathrm{~nm}$. 

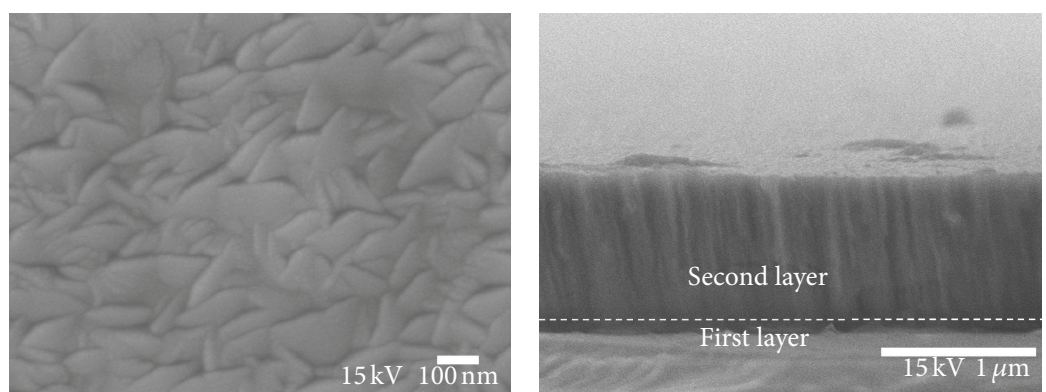

(a)
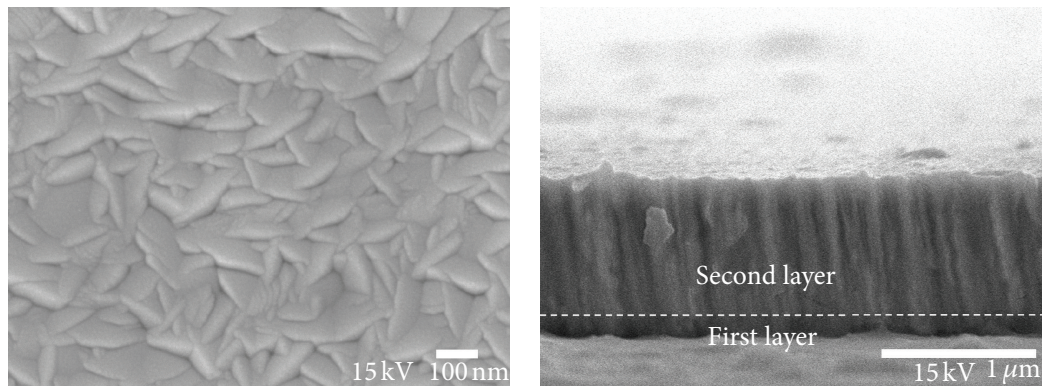

(b)
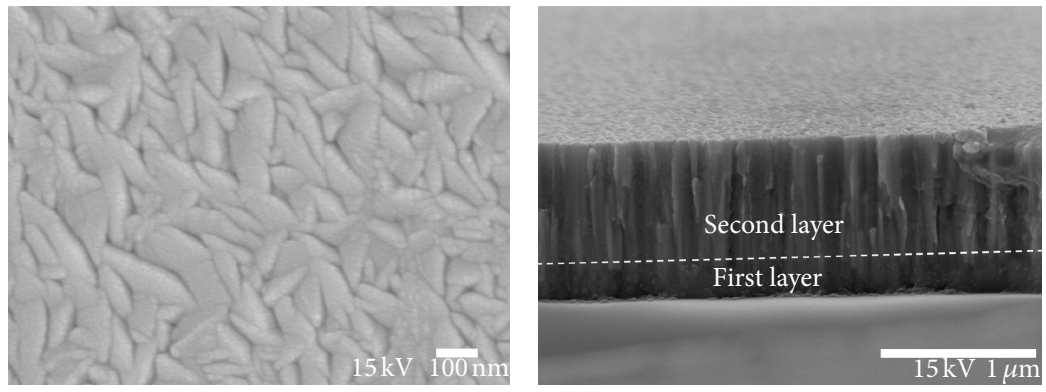

(c)
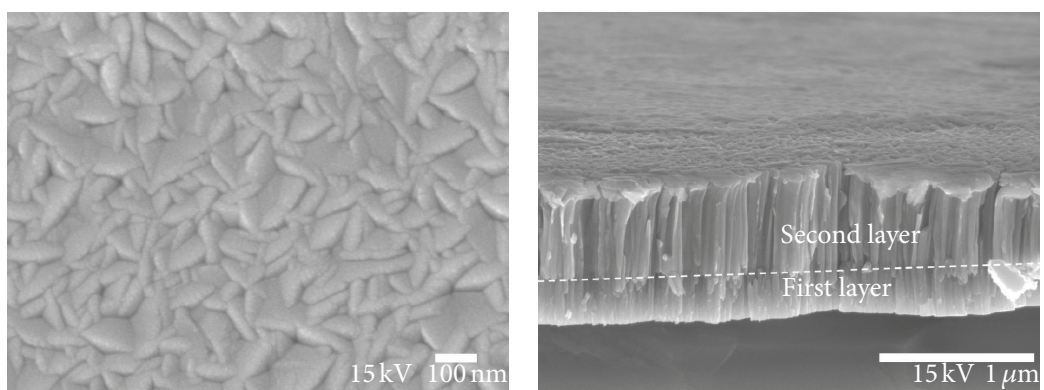

(d)
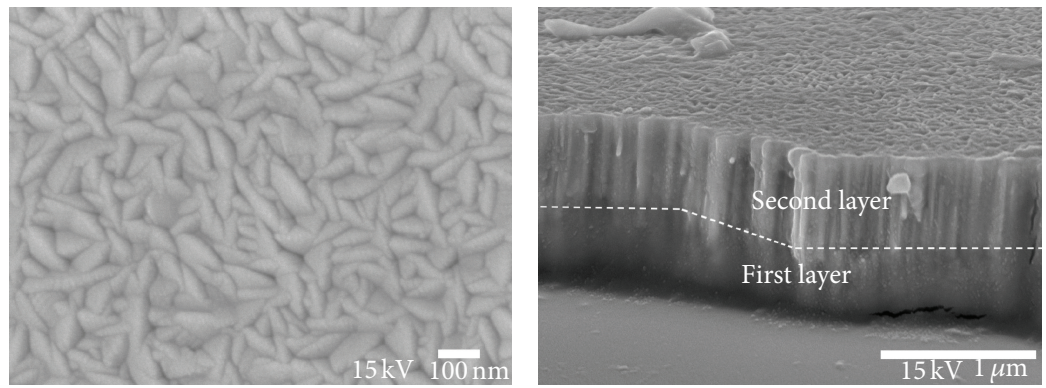

(e)

FIGURE 5: Surface (left) and cross-sectional (right) SEM micrographs of the Mo bilayer, corresponding to Table 5: (a) sample 1, (b) sample 2, (c) sample 3, (d) sample 4, and (e) sample 5. 


\section{Conclusions}

Molybdenum (Mo) thin films were grown on soda lime glass using a direct current (dc) magnetron sputtering system. The Taguchi method provides an effective experimental design method for the study of the effect of the sputtering parameters on the electrical, structural, and morphological properties of Mo films. The analysis of variance results for the electrical resistivity of the Mo films deposited demonstrate that the working pressure has a significant affect. The optimal deposition parameters for the sputtering of Mo thin films are a working pressure of 3 mTorr, a dc power of $400 \mathrm{~W}$, and a substrate temperature of $200^{\circ} \mathrm{C}$. For the Mo single layer system, the XRD results show that the crystallites of the films are mainly oriented in the (110) direction. In order to produce an optimal Mo film, with a lower resistivity and good adhesion, an Mo bilayer film is formed using a sequentially changing working pressure. In order to ensure optimum properties for the Mo bilayer, the 1st layer is deposited at 13 mTorr (thickness was $100 \mathrm{~nm}$ ), and the 2nd layer is deposited at 3 mTorr (thickness was $900 \mathrm{~nm}$ ), which ensures good adhesion, low resistivity $\left(1.79 \times 10^{-5} \Omega-\mathrm{cm}\right)$, and high reflectance $(58.80 \%)$.

\section{Acknowledgments}

The authors gratefully acknowledge the support of the Solar Applied Materials Technology Corporation, the Ministry of Education of Taiwan, through Grant nos. 101G-88-013, NSC 101-2514-S-003-004-, NSC 101-3113-S-262-001-, and NSC 101-2622-E-003-002-CC3, and the Chung-Shan Institute of Science \& Technology (Armaments Bureau).

\section{References}

[1] C. Y. Shi, Y. Sun, Q. He, F. Y. Li, and J. C. Zhao, " $\mathrm{Cu}(\mathrm{In}, \mathrm{Ga}) \mathrm{Se}_{2}$ solar cells on stainless-steel substrates covered with $\mathrm{ZnO}$ diffusion barriers," Solar Energy Materials and Solar Cells, vol. 93, no. 5, pp. 654-656, 2009.

[2] H. M. Wu, S. C. Liang, Y. L. Lin et al., "Structure and electrical properties of Mo back contact for $\mathrm{Cu}(\mathrm{In}, \mathrm{Ga}) \mathrm{Se}_{2}$ solar cells," Vacuum, vol. 86, pp. 1916-1919, 2012.

[3] F. Erfurth, Z. Jehl, M. Bouttemy et al., "Mo/Cu(In,Ga)Se $\mathrm{Se}_{2}$ back interface chemical and optical properties for ultrathin CIGSe solar cells," Applied Surface Science, vol. 258, pp. 3058-3061, 2012.

[4] K. Orgassa, H. W. Schock, and J. H. Werner, "Alternative back contact materials for thin film $\mathrm{Cu}(\mathrm{In}, \mathrm{Ga}) \mathrm{Se}_{2}$ solar cells," Thin Solid Films, vol. 431-432, pp. 387-391, 2003.

[5] S. A. Pethe, E. Takahashi, A. Kaul, and N. G. Dhere, "Effect of sputtering process parameters on film properties of molybdenum back contact," Solar Energy Materials \& Solar Cells, vol. 100, pp. 1-5, 2012.

[6] R. Singh and J. S. Khamba, "Taguchi technique for modeling material removal rate in ultrasonic machining of titanium," Materials Science and Engineering A, vol. 460-461, pp. 365-369, 2007.

[7] C. C. Chen, C. C. Tsao, Y. C. Lin, and C. Y. Hsu, "Optimization of the sputtering process parameters of GZO films using the
Grey-Taguchi method," Ceramics International, vol. 36, no. 3, pp. 979-988, 2010.

[8] L. Assmann, J. C. Bernède, A. Drici, C. Amory, E. Halgand, and M. Morsli, "Study of the Mo thin films and Mo/CIGS interface properties," Applied Surface Science, vol. 246, no. 1-3, pp. 159166, 2005.

[9] P. Blosch, S. Nishiwaki, T. Jaeger et al., "Alternative back contact designs for $\mathrm{Cu}(\mathrm{In}, \mathrm{Ga}) \mathrm{Se}_{2}$ solar cells on polyimide foils," Thin Solid Films. In press.

[10] H. L. Hsu, C. B. Yang, C. H. Huang, and C. Y. Hsu, "Electrical and optical studies of Ga-doped $\mathrm{ZnO}$ thin films," Journal of Materials Science, vol. 24, pp. 13-19, 2013.

[11] W. H. Yang and Y. S. Tarng, "Design optimization of cutting parameters for turning operations based on the Taguchi method," Journal of Materials Processing Technology, vol. 84, no. 1-3, pp. 122-129, 1998.

[12] P. S. Kao and H. Hocheng, "Optimization of electrochemical polishing of stainless steel by grey relational analysis," Journal of Materials Processing Technology, vol. 140, no. 1-3, pp. 255-259, 2003.

[13] S. J. Kim, K. S. Kim, and H. Jang, "Optimization of manufacturing parameters for a brake lining using Taguchi method," Journal of Materials Processing Technology, vol. 136, no. 1-3, pp. 202-208, 2003.

[14] Z. H. Li, E. S. Cho, and S. J. Kwon, "Molybdenum thin film deposited by in-line DC magnetron sputtering as a back contact for $\mathrm{Cu}(\mathrm{In}, \mathrm{Ga}) \mathrm{Se}_{2}$ solar cells," Applied Surface Science, vol. 257, pp. 9682-9688, 2011.

[15] A. E. H. B. Kashyout, H. M. A. Soliman, H. A. Gabal, P. A. Ibrahim, and M. Fathy, "Preparation and characterization of DC sputtered molybdenum thin films," Alexandria Engineering Journal, vol. 50, no. 1, pp. 57-63, 2011.

[16] M. Jubault, L. Ribeaucourt, E. Chassaing, G. Renou, D. Lincot, and F. Donsanti, "Optimization of molybdenum thin films for electrodeposited CIGS solar cells," Solar Energy Materials and Solar Cells, vol. 95, no. 1, pp. S26-S31, 2011. 

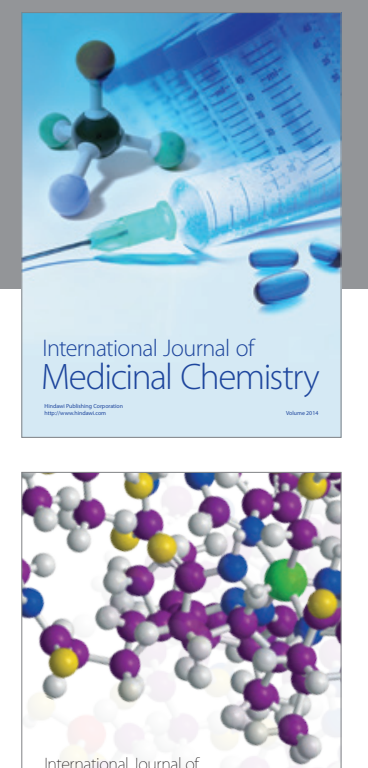

\section{Carbohydrate} Chemistry

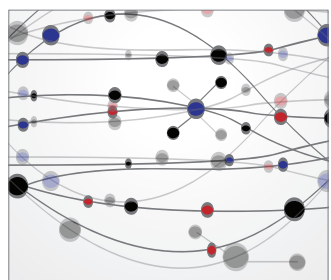

The Scientific World Journal
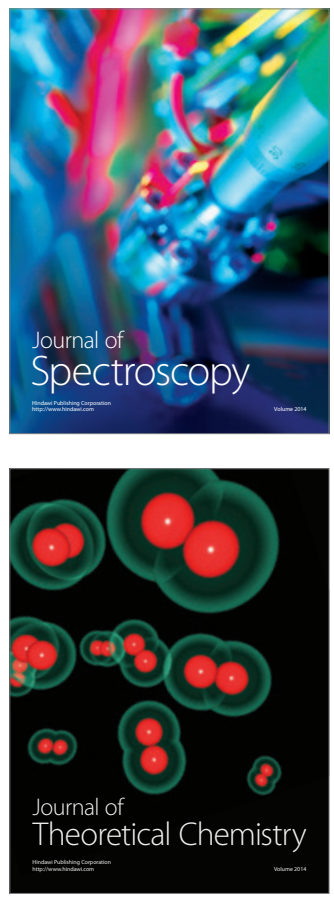
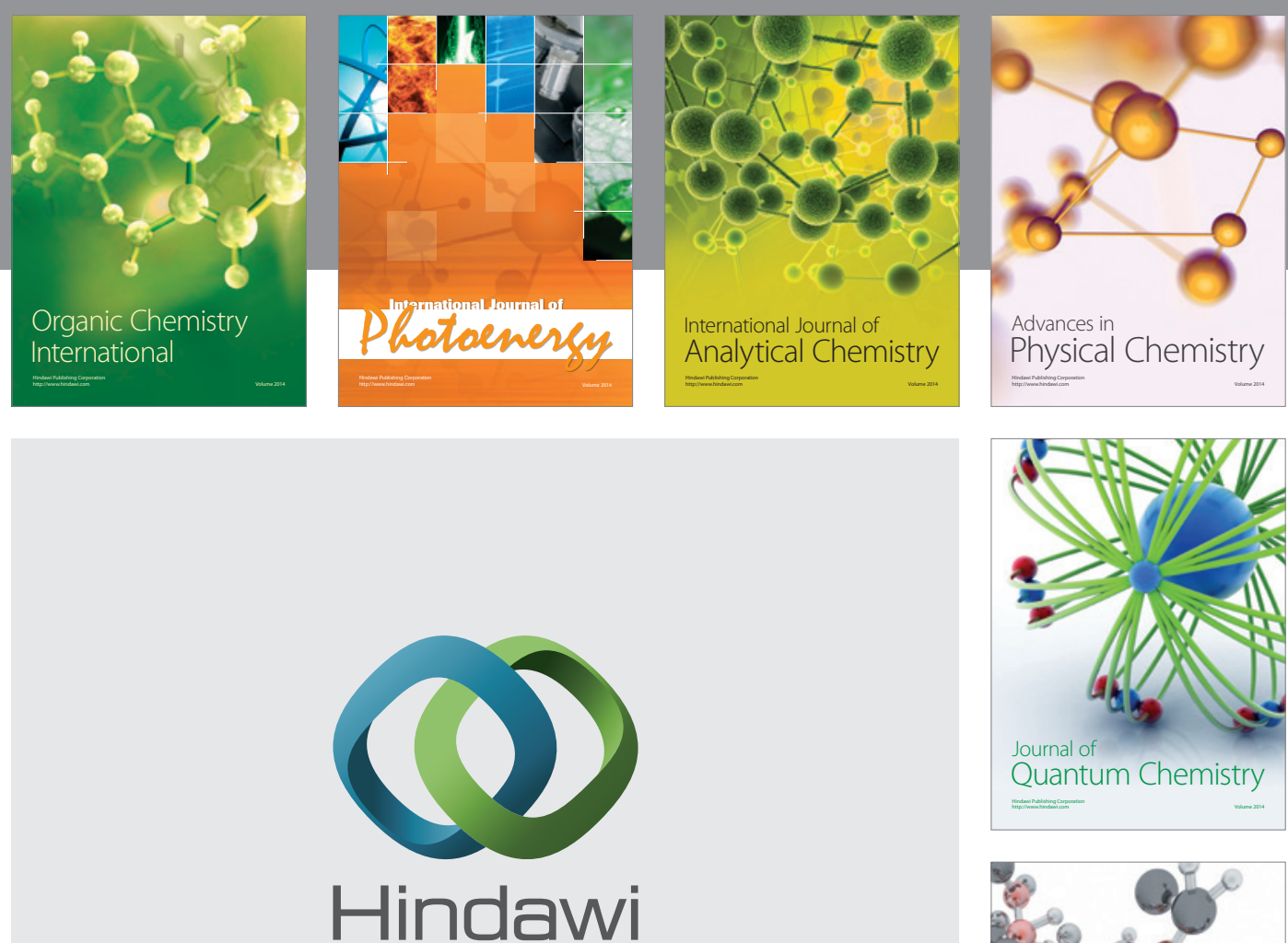

Submit your manuscripts at

http://www.hindawi.com

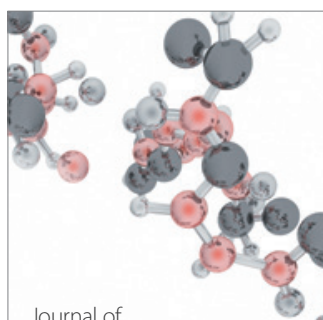

Analytical Methods

in Chemistry

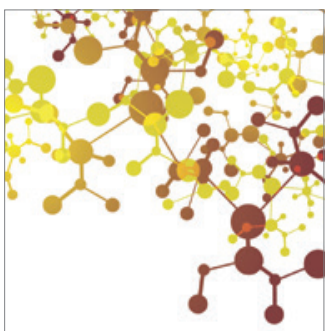

Journal of

Applied Chemistry

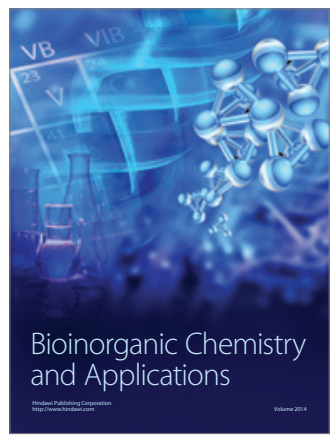

Inorganic Chemistry
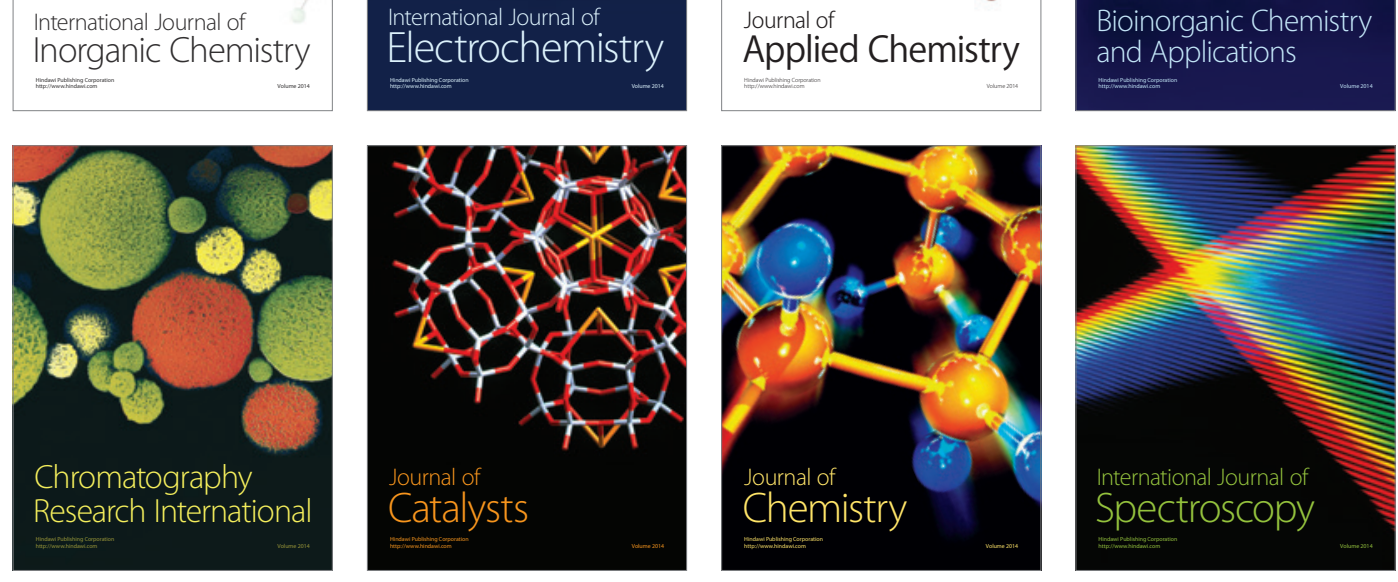